\title{
0 papel da expressão de Bcl-2 em material obtido por PAAF no diagnóstico de doenças linfoproliferativas B
}

Primeira submissão em 07/08/08 Última submissão em 10/12/08 Aceito para publicação em 10/12/09 Publicado em 20/12/08

\author{
The role of $\mathrm{BCl}-2$ expression in fine needle aspiration specimens for the diagnostic accuracy in \\ lymphoproliferative diseases
}

Carolina Escaramuzi Lourenço'; Elisa Y. S. Kimura²; Alex Freire Sandes³; Antônio Corrêa Alves4; Gisele Wally Braga Colleonis; Wolney Góis Barreto ${ }^{3}$; Leina Y. Etto ${ }^{3}$; Mihoko Yamamoto ${ }^{6}$

unitermo
PAAF
Linfoma
BCl-2
DLP
Citometria de fluxo
Imunofenotipagem

\section{resumo}

Introdução: O diagnóstico das doenças linfoproliferativas (DLP) tradicionalmente baseia-se no estudo histológico dos linfonodos (LN) acrescido de imuno-histoquímica. A imunofenotipagem (IFT) pela citometria de fluxo (CF) é uma ferramenta sensível e rápida, que pode ser aplicada nas DLP, em material obtido por punção aspirativa por agulha fina (PAAF) de LN. O Bcl-2 é um proto-oncogene que se expressa em várias DLP, porém em níveis especialmente elevados no linfoma folicular (LF). Objetivos: Diagnosticar DLP, através de morfologia e imunofenotipagem por CF, em amostras obtidas por PAAF de LN. Material e método: Amostras de 25 pacientes com adenopatias e de duas tonsilas reacionais foram analisadas pela morfologia e IFT, utilizando um painel inicial de AcMo (CD3, CD4, CD8, CD19, anti-kappa; e anti-lambda;), ampliado conforme a necessidade (CD5, CD10, CD11c, CD23, CD79b, slgM, FMC-7 e Bcl-2). Os resultados foram comparados com a histologia. Resultados: Dos 25 casos, quatro foram classificados como reacionais e 21 como DLP-B, havendo concordância com resultados histológicos em todos os casos. A intensidade média de fluorescência (IMF) da Bcl-2 no LF $(19,92)$ foi maior que em outras DLP-B $(11,93)$ e que nos controles $(3,49)(p=0,032)$. Conclusão: A PAAF de LN combinada com a citomorfologia e a IFT por CF permite uma rápida diferenciação entre os processos reacionais e linfoproliferativos $B$. A elevada expressão da Bcl-2 nos LFs pela citometria mostra sua utilidade no diagnóstico do tipo mais freqüente das DLP-B. A obtenção de células por PAAF requer treinamento e recomendamos mais de uma punção.

\section{abstract}

Background: The diagnosis of lymphoproliferative disorders (LPD) is routinely made through histological and immunohistochemical analysis of lymph nodes. Immunophenotyping by flow cytometry (FC) is a sensitive and fast tool, which may be applied in samples obtained through fine needle aspiration for the diagnosis of LPD. BCl-2 is a proto-oncogene that appears in several LPD and it has a significantly high expression in follicular lymphomas. Objectives: to diagnose LPD in FNA samples through morphology and flow cytometry immunophenotyping. Material and methods: Samples from 25 patients with lymphadenopathies and 2 reactive tonsils were studied through morphology and immunophenotyping. The antigens expressions were evaluated by using a screening panel of monoclonal antibodies (CD3, CD4, CD8, CD19, light chains kappa; and lambda), followed by CD5, CD10, CD11c, CD23, CD79b, slgM, FMC-7 and BCl-2 when required. The results were compared with histology. Results: Four out of 25 samples were reactive processes and 21 were B-LPD. In all cases there was consistency with histological results. The mean fluorescence intensity of BCl-2 in Follicular Lymphoma (19.92) was higher compared with other lymphoproliferative diseases (11.93) and controls (3.49) ( $p=0.032)$. Conclusion: Fine needle aspiration of lymph nodes associated with cytomorphology and flow cytometry immunophenotyping allows a fast differentiation between reactive processes and $B$ lymphoproliferative cases. The high expression of $B C l-2$ by cytometry shows its usefulness in the diagnosis of the most frequent type of B-LPD. Fine needle aspiration sampling requires training and more than one aspiration is recommended.

\section{key words}

Fine needle aspiration

Lymphoma

Bcl-2

LPD

Flow cytometry

Immunophenotyping

1. Farmacêutica bioquímica; mestre em Ciências pela Universidade Federal de São Paulo (UNIFESP).

2. Farmacêutica bioquímica; pesquisadora da disciplina de Hematologia e Hemoterapia da UNIFESP.

3. Médicos hematologistas; alunos de pós-graduação da disciplina de Hematologia e Hemoterapia da UNIFESP.

4. Professor adjunto do Departamento de Anatomia Patológica da UNIFESP.

5. Professora livre-docente da disciplina de Hematologia e Hemoterapia da UNIFESP.

6. Professora associada da disciplina de Hematologia e Hemoterapia da UNIFESP.

Trabalho realizado na disciplina de Hematologia e Hemoterapia da UNIFESP.

Suporte financeiro: Fundação de Amparo à Pesquisa do Estado de São Paulo (FAPESP), processo 05/57792-0). 


\section{Introdução}

Nas últimas duas décadas, a análise de marcadores imunológicos dos linfócitos pela imunofenotipagem (IFT) evoluiu rapidamente de uma utilização restrita à área de pesquisas para a introdução nas rotinas de diagnóstico laboratorial. Essa expansão é justificada principalmente pela ampla disponibilização dos citômetros de fluxo e de grande quantidade de anticorpos monoclonais que rapidamente detectam tanto antígenos de membrana como intracelulares em diferentes suspensões celulares ${ }^{(19)}$.

O estudo imunofenotípico nos processos linfoproliferativos é útil na distinção entre alterações reacionais e malignas, através da identificação de clonalidade, principalmente nas neoplasias de células $B$, onde se verifica restrição de uma das cadeias leves. Além da aplicação no diagnóstico, a IFT é de fundamental importância na classificação dos diferentes tipos e subtipos das doenças linfoproliferativas (DLP) ${ }^{(9)}$.

O método diagnóstico clássico das DLP baseia-se na histologia e nas reações imuno-histoquímicas aplicadas em material de biópsia de linfonodos (LN). Apesar das vantagens desse método, como a análise da arquitetura do tecido, o seu procedimento é demorado, além de ser invasivo.

Por outro lado, a classificação da Organização Mundial da Saúde (OMS) atualmente utilizada, além de enfatizar o aspecto histológico, considera dados clínicos, citológicos, imunofenotípicos e genotípicos para a caracterização diagnóstica e prognóstica dos diferentes tipos de DLP. Assim, novos marcadores altamente específicos para aprimorar a classificação e oferecer informações sobre o prognóstico dessas doenças são continuamente descritos, podendo os painéis de anticorpos monoclonais incorporá-los de acordo com o objetivo ${ }^{(22)}$. A demonstração da expressão da oncoproteína reguladora da apoptose Bcl-2 em células B foliculares tem sido particularmente útil na diferenciação de processos reacionais e neoplásicos, encontrando-se altamente expressa em aproximadamente 85\% dos casos de linfoma folicular (LF).

A punção aspirativa por agulha fina (PAAF) é uma técnica rápida, simples, segura e pouco invasiva para a obtenção de células com boa preservação para vários estudos, incluindo a IFT por citometria de fluxo (CF) ${ }^{(20)}$.

\section{Objetivos}

Este estudo objetivou estabelecer o diagnóstico rápido das DLP através de análise morfológica e imunofenotí- pica por citometria de fluxo em material de linfonodos obtidos por PAAF.

\section{Material e método}

Vinte e cinco pacientes com linfonodomegalias atendidos no Hospital São Paulo da Universidade Federal de São Paulo (UNIFESP) foram incluídos no estudo, sendo seis do gênero feminino (24\%) e 19 do masculino (76\%), com mediana de idade de 59 anos. Anatomicamente, os aspirados foram obtidos do linfonodo de maior tamanho e melhor acessibilidade: região cervical ( $n=15)$, axilar $(n=3)$, inguinal $(n=5)$, submandibular $(n=1)$ e coxa $(n=1)$. Como controles foram estudadas duas amostras de tonsilas palatinas reacionais de dois pacientes submetidos à tonsilectomia. As células em suspensão foram obtidas através de maceração do tecido com auxílio de bisturi e lavagem em meio desenvolvido no Roswell Park Memorial Institute (RPMI), seguido de passagem por filtro de náilon $30 \mu \mathrm{m}$ (Miltenyi Biotec). Com esse material foram também preparadas duas lâminas por citocentrifugação (cytospin), para análise citomorfológica.

A biópsia de $L N$ foi realizada em todos os pacientes para diagnóstico histológico e imuno-histoquímico. Todos os pacientes, bem como os controles, foram esclarecidos a respeito do estudo, sendo a coleta de material realizada mediante o consentimento informado prévio.

\section{Técnica de PAAF}

O material de aspirado de LN foi obtido com a utilização de agulha $22 \mathrm{G}$ acoplada a uma seringa de $10 \mathrm{ml}$ ou $20 \mathrm{ml}$ sem anticoagulante. Nos três últimos casos, a coleta foi realizada com auxílio de um citoaspirador (Valeri, MPJ Equipamentos, Ribeirão Preto). As células foram imediatamente transferidas para tubo de ácido etilenodiaminotetracético (EDTA) contendo $2 \mathrm{ml}$ de meio de cultura RPMI, e o processamento da IFT ocorreu no mesmo dia da coleta.

\section{Estudo citológico}

Uma gota do aspirado foi utilizada para a confecção de um a dois esfregaços em lâminas que foram corados pelo método de May-Grüwald-Giemsa. A morfologia foi avaliada 
por dois examinadores independentes em microscopia ótica comum.

\section{Imunofenotipagem por citometria de fluxo}

Para o estudo da expressão de antígenos de superfície, as células foram lavadas três vezes em $2 \mathrm{ml}$ de solução salina fosfatada tamponada (PBS), e o número final de células foi ajustado para $1 \times 10^{6} / \mathrm{ml}$.

Inicialmente foi aplicado um painel de triagem composto pelos anticorpos anti-CD3 (Pharmingen), anti-CD4 $(B D)$, anti-CD8 (BD), anti-CD19 (BD), anti-k (BD), anti- $\lambda$ (Pharmingen). Quando caracterizada presença de clonalidade, foi aplicado o painel completo de anticorpos, incluindo CD23 (Immunotech), CD79b (Pharmingen), FMC-7 (DAKO), slgM (DAKO), CD5 (Pharmingen), CD10 (Coulter), CD11c (BD), CD45 (BD) e Bcl-2 (DAKO), sempre que a celularidade permitisse.

As células foram incubadas com os AcMo (em proporções recomendadas pelo fabricante ou após titulação de cada anticorpo) durante 15 minutos à temperatura ambiente e sob proteção da luz. Para a lise de hemácias utilizou-se $500 \mu \mathrm{l}$ da solução comercial FACS Lysing Solution (Becton Dickinson) e incubação por 10 minutos. As células foram então lavadas uma vez em $3 \mathrm{ml}$ de PBS contendo azida $0,1 \%$ e fixadas com $0,5 \mathrm{ml}$ de solução de formaldeído $1 \%$.

Para a marcação dos antígenos intracelulares $\mathrm{BCl}-2$, imunoglobulina da classe $\mathrm{M}$ (IgM) e cadeias leves das imunoglobulinas ( $\kappa$ e $\lambda$ ) realizou-se o processo de fixação e permeabilização utilizando-se o kit Intraprep (Immunotech).

A coleta e a análise dos dados foram realizadas no citômetro de fluxo FACSCalibur (Becton-Dickinson, San Jose, CA), utilizando-se os programas CellQuest (BectonDickinson) e Paint-a-Gate Pro (Becton-Dickinson).

\section{Diagnóstico e subclassificação das DLP}

Foram estabelecidos seguindo-se os critérios de classificação da OMS para doenças linfoproliferativas, levando-se em consideração os aspectos citomorfológicos e imunofenotípicos das células.

\section{Resultados}

Foram coletadas amostras de 31 pacientes com linfadenopatias, sendo 25 estudados pela CF. Não foi possível avaliar o imunofenótipo em seis casos pelo material escassamente celular, principalmente nas primeiras coletas e quando se realizava apenas uma única punção. O rendimento foi melhorado com a experiência do médico e também quando se passou à realização de mais de uma punção no mesmo linfonodo. Pelo exame histológico foram diagnosticados quatro casos de linfadenomegalia reacional, um caso de linfoma de Hodgkin (LH) e 20 DLP-B: sete casos de linfoma folicular (LF), seis casos de linfoma difuso de grandes células (LDGC), dois casos de linfoma linfocítico de pequenas células (LLPC), um caso de cada de linfoma do manto (LM), linfoma da zona marginal, linfoma linfoblástico, linfoma do tecido linfóide associado à mucosa (MALT) e linfoma de Burkitt (Tabela 1). Não houve nenhum caso de DLP de células T.

Na Tabela 1 encontram-se os resultados da IFT (CD3, CD4, CD8, CD19, cadeias $\kappa$ e $\lambda, C D 5, C D 10, C D 11 c$, CD23 e CD79b) dos 25 casos de $L N$ e dois controles (tonsilas), agrupados de acordo com o resultado do exame histológico.

Os dois casos de tonsilas reacionais mostraram predomínio de células B (64\% e $83 \%)$ sobre as células $\mathrm{T}$, com ambas as subpopulações $\kappa+\mathrm{e} \lambda+$ presentes. As células T apresentaram ambas populações CD4+ e CD8+, preservando a proporção normal.

Todos os casos de linfadenomegalia reacional apresentaram predomínio de células $T$ (68\%), com presença concomitante de células CD4+ e CD8+, com predomínio de CD4 esperado. A média da porcentagem de células $B(C D 19+)$ foi $9,6 \%$, com presença de ambas as células $B \kappa+$ e $B \lambda+$.

Nos casos proliferativos, ao contrário das amostras reacionais, houve predomínio de células $B$ sobre as células $T$ em 15 dos 21 casos, sugerindo processo linfoproliferativo B (Figura 1). Houve restrição de uma das cadeias leves, confirmando a clonalidade $B$ (oito casos $B / \kappa+$, quatro $B / \lambda+$, um caso $B \kappa-/ \lambda-$, um caso $B \kappa+/ \lambda+e$ um caso $B / \kappa+e B / \lambda+$ ). Nas quatro (todos foram LDGC$B$ pela histologia) amostras onde houve predomínio de células $T$, foi possível verificar restrição de uma das cadeias leves nas células $B$ de três amostras, caracterizando clonalidade $B$ nesses casos. Em duas amostras, ambas as células $B / \kappa+$ e $B / \lambda+$ estavam presentes. Em um caso (LDGC-B) houve quantidade semelhante de células T e $B$ e neste não foi realizado estudo das cadeias $\kappa$ e $\lambda$ por insuficiência de células, havendo também forte componente dilucional. 
Expressão dos antígenos nas células dos linfonodos e tonsilas reacionais e nas DLP diagnosticadas pelo

Tabela 1 exame histopatológico

\begin{tabular}{|c|c|c|c|c|c|c|c|c|c|c|c|}
\hline $\begin{array}{l}\text { Diagnóstico } \\
\text { histológico }\end{array}$ & $\begin{array}{l}\text { CD3 } \\
(\%)\end{array}$ & $\begin{array}{l}\text { CD4 } \\
(\%)\end{array}$ & $\begin{array}{l}\text { CD8 } \\
(\%)\end{array}$ & $\begin{array}{l}\text { CD19 } \\
(\%)\end{array}$ & $\kappa(\mathrm{N}+)$ & $\lambda(\mathrm{N}+)$ & $\begin{array}{l}\mathrm{CD5} \\
(\mathrm{N}+)\end{array}$ & $\begin{array}{l}\mathrm{CD} 10 \\
\left(\mathrm{~N}_{+}\right)\end{array}$ & $\begin{array}{c}\text { CD11C } \\
\left(\mathrm{N}_{+}\right)\end{array}$ & $\begin{array}{l}\mathrm{CD} 23 \\
(\mathrm{~N}+)\end{array}$ & $\begin{array}{l}\mathrm{CD79b} \\
(\mathrm{N}+)\end{array}$ \\
\hline $\begin{array}{l}\text { Tonsila } \\
\text { reacional } \\
\text { (média) } \\
(n=2)\end{array}$ & 26,3 & 72,7 & 24,8 & 73,5 & $2 / 2$ & $2 / 2$ & & & & & \\
\hline $\begin{array}{l}\text { LN reacional } \\
\text { (média) } \\
(n=4)\end{array}$ & 68,1 & 49,7 & 36,1 & 9,6 & $4 / 4$ & $4 / 4$ & & & & & \\
\hline $\begin{array}{l}\text { L. folicular } \\
\text { (média) } \\
(n=7)\end{array}$ & 21,4 & 70 & 29,6 & 74,4 & $2 / 7^{*}$ & $4 / 7^{*}$ & $0 / 7$ & $5 / 7$ & $2 / 6$ & $3 / 7$ & $5 / 7$ \\
\hline $\begin{array}{l}\text { LDGC-B } \\
\text { (média) } \\
(n=6)\end{array}$ & 38,2 & 61,4 & 34,5 & 43,7 & $4 / 5^{\#}$ & $3 / 5^{\#}$ & $1 / 5$ & $1 / 4$ & $2 / 2$ & $2 / 5$ & $3 / 5$ \\
\hline $\begin{array}{l}\text { LLPC (média) } \\
(n=2)\end{array}$ & 10,2 & 57,2 & 41,2 & 88,9 & $2 / 2$ & $0 / 2$ & $1 / 1$ & $0 / 2$ & $1 / 2$ & $0 / 2$ & $2 / 2$ \\
\hline $\begin{array}{l}\text { Linfoma manto } \\
(n=1)\end{array}$ & 35,4 & 63,3 & 29,3 & 47,5 & 1 & 0 & 1 & 0 & NR & 0 & NA \\
\hline $\begin{array}{l}\text { L.Z. marginal } \\
(n=1)\end{array}$ & 10,4 & 37 & 48 & 85,4 & $1^{* *}$ & $1^{* *}$ & 0 & 0 & 0 & 0 & 0 \\
\hline $\begin{array}{l}\text { L. linfobástico } \\
(n=1)\end{array}$ & 17,9 & 36,9 & 57,8 & 76,1 & 1 & 0 & 0 & 0 & 1 & 1 & 1 \\
\hline $\begin{array}{l}\text { L. MALT } \\
(n=1)\end{array}$ & 8,9 & 26,9 & 60 & 89,9 & 1 & 0 & 1 & 0 & 0 & 0 & 0 \\
\hline $\begin{array}{l}\text { L. Burkitt } \\
(n=1)\end{array}$ & $<1$ & $<1$ & $<1$ & 82 & 1 & 0 & 0 & 1 & 0 & 0 & 1 \\
\hline $\begin{array}{l}\text { L. Hodgkin } \\
(n=1)\end{array}$ & 55 & 76 & 21 & 37 & 1 & 1 & NR & NR & NR & NR & NR \\
\hline
\end{tabular}

(\%): \% de células positivas; CD4 e CD8: \% das células T (CD3+) CD4+ ( $N+) n^{\circ}$ de casos positivos ( $\geq 20 \%$ )/total; NR: não-realizado; NA: não-avaliável. LN: linfonodos; ${ }^{*} 1$ caso $(\kappa-/ \lambda-)$; \#2 casos $(\kappa+/ \lambda+)$ e 1 caso não-realizado; ${ }^{*} 1$ caso (coexpressão $\kappa$ e $\lambda$ ).
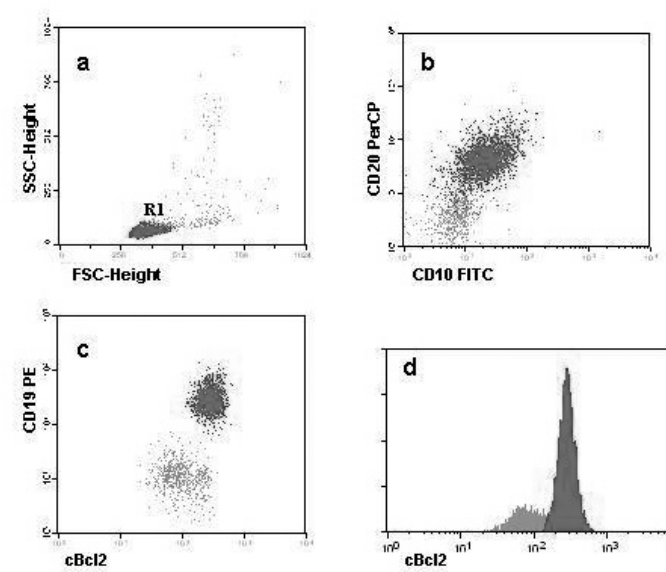

CD10 FITC

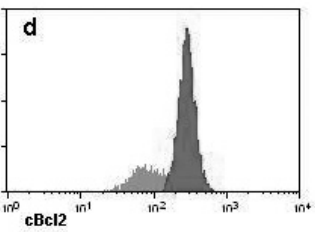

Figura 1 - Representação gráfica da análise em citometria de fluxo de um caso de linfoma folicular. a) Distribuição em dot plot das células selecionadas na região $R 1$ pelo tamanho (FSC) e granularidade (SSC); b) células B da região $R 1$ (em cor vermelha) positivas para $\mathrm{CD} 20$ e $\mathrm{CD} 10 ; \mathrm{c})$ as células $B(\mathrm{CD} 19+)$ apresentam alta expressão de $B C l-2 ; d)$ histograma da intensidade de fluorescência da BCl-2 nas células B 
Nos três casos onde havia presença de ambas as populações $B / \kappa+e B / \lambda+$, a citologia era de células "atípicas" revelando presença de neoplasia linfóide em dois casos e de células de Hodgkin em um, conforme mostrado na Tabela 2.
O diagnóstico e a classificação das DLP estabelecidos pela citologia e pela imunofenotipagem do material obtido por PAAF encontram-se na Tabela 2 juntamente com os respectivos resultados histológicos.

\section{Tabela 2}

Diagnóstico histológico

Hiperplasia linfóide reacional* $(n=4)$

Hiperplasia linfóide

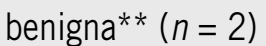

Linfoma folicular\# $(n=6)$

Linfoma folicular $(n=1)$

LDGC-B $(n=3)$

$\operatorname{LDGC-B}(n=2)$

Sugestivo de

L. manto

L. folicular?

Manto forma

blastóide?

LDGC-B $(n=1)$

Sugestivo de LNH de células de tamanho médio

L. células do manto

LLPC? Reacional?

$(n=1)$

L. Burkitt $(n=1)$

$\operatorname{LLPC}(n=1)$

LNH manto?

$\operatorname{LLPC}(n=1)$

Sugestivo de L. Burkitt

Sugestivo de LNH de

pequenas células

Sugestivo de LNH de pequenas células

L. zona marginal

$(n=1)$

L. linfoblástico

$(n=1)$

$\operatorname{MALT}(n=1)$
Sugestivo de LNH de pequenas células

Sugestivo de LNH de grandes células

Sugestivo de LNH de pequenas células/células médias
Imunofenotipagem (CF)

Ausência de clonalidade

Ausência de clonalidade

Sugestivo de linfoma folicular

Sugestivo de DLPB-к

Sugestivo de DLP-B

DLPB, LDGC?
Citologia + imunofenotipagem

(CF)

Processo reacional

Processo reacional**

Linfoma folicular

Sugestivo de DLPB-к

Sugestivo de L. folicular

Sugestivo de DLP-B

DLP-B

Sugestivo de L. células do

LNH manto

manto

Sugestivo de linfoma folicular

L. Burkitt

Sugestivo de DLPB-к

LNH de pequenas células

Sugestivo de DLPB-к

DLPB-к

Sugestivo de DLP-B com

Sugestivo de DLP-B com coexpressão $\kappa / \lambda$ coexpressão $\kappa / \lambda$

Sugestivo de DLPB-к

DLPB-к

Sugestivo de L. células

DLPB-א do manto
Sugestivo de L. Hodgkin?

L. Hodgkin $(n=1) \quad$ Sugestivo de L. Hodgkin? Sem clonalidade Sugestivo de
LNH: linfoma não-Hodgkin; *linfonodo reacional; **tonsila reacional; \#1 caso definido pelo Bcl-2 elevado; CF: citometria de fluxo. 
No estudo citomorfológico, um caso de tonsila não permitiu análise devido à má qualidade da lâmina de cytospin; o outro apresentava células heterogêneas, com predomínio de linfócitos maduros de tamanho variável, sem figuras de mitose. Quatro LN apresentavam as mesmas características citológicas e foram concluídos como sugestivos de processos reacionais.

$\mathrm{Na}$ imunofenotipagem dessas amostras, conforme apresentado na tabela anterior, confirmou-se ausência de clonalidade.

A análise citológica dos demais materiais obtidos por PAAF sugeriu o diagnóstico de DLP em 20 casos, inclusive os subtipos LDGC e linfoma de Burkitt (LB) e LH pela presença das células morfologicamente características (Figura 2). Morfologicamente, o LH apresentou-se hipocelular, com presença de linfócitos maduros, células gigantes de núcleo lobulado e vários nucléolos evidentes, altamente sugestivas de malignidade.

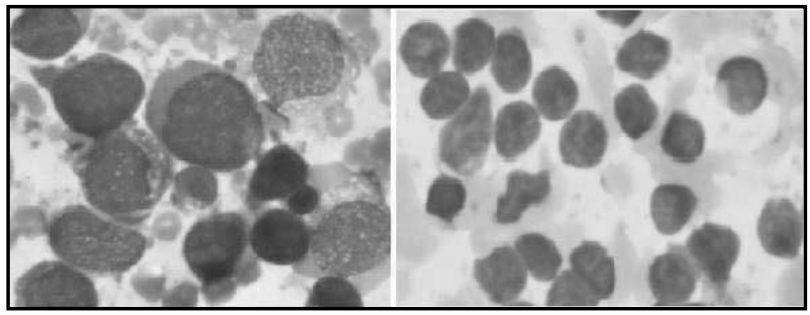

Figura 2 - Aspectos citomorfológicos de materiais de linfonodos obtidos por PAAF corados pela técnica de May-Grünwald-Giemsa. À esquerda um caso de linfoma difuso de grandes células e à direita, um caso de linfoma folicular
A citologia de um caso não permitiu diferenciação entre processo reacional e DLP, devido à heterogeneidade de células (linfócitos pequenos, células histiocitárias, alguns polimorfonuclerares). O exame imunofenotípico, no entanto, sugeriu diagnóstico de linfoma de células do manto.

A imunofenotipagem das amostras de PAAF possibilitou diferenciar o processo proliferativo do reacional em todos os casos, exceto no LH, pela ausência de clonalidade das células.

O resultado da análise conjunta de citologia e IFT foi comparado com o resultado dos respectivos exames histológicos dos LN. Todos os casos reacionais (tonsilas e LN) foram confirmados pela histologia.

Das DLP, 12 (57\%) amostras tiveram subclassificação correta em comparação com o histológico: $86 \%$ dos casos de LF (seis em sete), 50\% (três em seis) de LDGC; um LM; um $L B$, um $L H$.

O subtipo foi sugerido com acerto em um caso de LLPC e não foi possível em seis amostras (um LLPC, um LF, um LDGC, um L. linfoblástico, um MALT e um linfoma da zona marginal) devido à falta de marcadores de superfície característicos. Os resultados não corresponderam aos do histológico em dois casos de LDGC, nos quais foram sugeridos como LF e LM, devido à expressão do CD10 e do $\mathrm{CD} 5$, respectivamente.

A expressão da proteína Bcl-2 estudada nas células B nos materiais de PAAF e de tonsilas está apresentada na Tabela 3.

\section{Tabela 3}

Expressão em intensidade média de fluorescência (IMF) da proteína Bcl-2 em células B de tonsila e de DLP

\begin{tabular}{lccccc}
\hline Bcl-2 & Tonsila & $\begin{array}{c}\text { L. folicular } \\
(n=7)\end{array}$ & $\begin{array}{c}\text { LDGC-B } \\
(n=3)\end{array}$ & $\begin{array}{c}\text { LLPC } \\
(n=2)\end{array}$ & Demais DLPB \\
IMF & 4,04 & 7,65 & 5,26 & 13,47 & $16,79^{\mathrm{a}}$ \\
& 2,94 & 5,35 & 2,53 & 4,92 & $1,9^{\mathrm{b}}$ \\
& & 27,94 & 2,31 & & $7,61^{\mathrm{c}}$ \\
& & 56,35 & 5,62 & & $2,93^{\mathrm{d}}$ \\
& & 24,67 & & & \\
& & 4,98 & & & \\
Média & 12,52 & & 9,2 & 6,31 \\
DP & 3,49 & 19,92 & 3,93 & 6,05 & 5,28 \\
Mediana & 0,78 & 18,51 & 1,75 & - &
\end{tabular}

aZona marginal, 'b. linfoblástico; 'MALT; 'L. Burkitt; IMF: IMF da população/IMF controle negativo IgG1; DP: desvio padrão. 
A expressão dessa proteína nas células controle de tonsilas foi baixa com valores IMF de 4,04 e 2,94. A média da intensidade do $\mathrm{BCl}-2$ nas células $B$ das DLP (média 11,93) foi maior que nas células $B$ das tonsilas.

A análise dos diferentes subtipos revelou que a IMF do BCl-2 no subgrupo do LF (média 19,92) foi mais elevada em relação à das células $B$ das tonsilas e dos $\mathrm{LDGC}-\mathrm{B}$ e demais $\operatorname{DLPB}(p=0.032)$ (Figura 3).

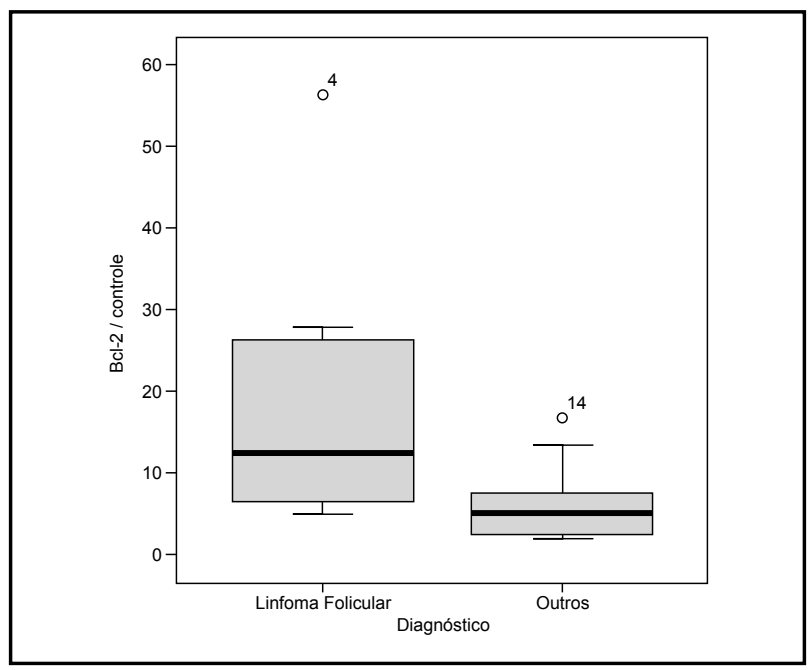

Figura 3 - Diferença de expressão da proteína Bcl-2 em linfócitos B de linfoma folicular e de outras doenças linfoproliferativas crônicas $B$. Os valores estão relatados em intensidade média relativa de fluorescência. As caixas representam os valores de percentis 25 e 75; a linha do meio e as linhas verticais correspondem ao valor de mediana e aos percentis 10 e 90 respectivamente ( $\mathrm{p}=0,032$; teste de Mann-Whitney)

\section{Discussão}

A classificação Revised European American Lymphoma (REAL), adotada pela OMS, incorporou novos critérios para o diagnóstico e a subclassificação dos linfomas além da arquitetura do tecido estudada pela histologia. Neoplasias com fenótipos e morfologias características podem ser classificadas utilizando-se material obtido por PAAF associado à complementaridade de análise morfológica e imunofenotipagem

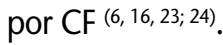

A confecção de esfregaços de boa qualidade técnica mostra-se útil, uma vez que o diagnóstico diferencial pode ser dado com base na composição celular (monomórfica; polimórfica; de pequeno, médio ou grande tamanho) ${ }^{(1)}$. Cuidado deve ser tomado em materiais com importante componente hemodilucional, podendo-se diagnosticar erroneamente como reacional um caso proliferativo.

A avaliação morfológica imediata da amostra obtida após a punção permite indicar, se necessário, uma nova coleta e obter uma amostra com celularidade mais adequada. Em nossa experiência conquistada ao longo do estudo, maior quantidade de células foi obtida com o treinamento do profissional que realizou as coletas e pela repetição da punção mais de uma vez no mesmo $L N$.

Nos subtipos linfoma difuso de grandes células (LDGC), linfoma de Burkitt (LB) e no $\mathrm{LH}$, a análise citológica do material obtido por PAAF foi muito útil na identificação, devido às suas características morfológicas peculiares.

Em biópsias de linfonodos e outros tecidos, a imuno-histoquímica é uma ferramenta importante, pois, preservando a morfologia celular e o padrão de arquitetura do tecido, permite a análise imunofenotípica em cortes histológicos ${ }^{(14)}$. Apesar dessa evidente vantagem, a técnica apresenta algumas limitações relacionadas com o procedimento técnico laborioso, a interferência de artefatos de coloração e a sua natureza semiquantitativa ${ }^{(2,14)}$.

Nesse contexto, a CF oferece maior sensibilidade, reduzindo a subjetividade na interpretação dos achados com muito maior rapidez, devendo ser utilizada sempre que possível, através da PAAF, principalmente nos casos de emergência clínica em que se requer rápido diagnóstico para pronta intervenção terapêutica. Além disso, é uma técnica altamente sensível na distinção entre linfocitose reacional e proliferativa, permitindo identificação de células neoplásicas através da caracterização da clonalidade ou da presença de fenótipos aberrantes ${ }^{(8)}$.

Em linfonodos normais, as células $B$ constituem cerca de $40 \%$ dos linfócitos, e as células T, aproximadamente $55 \%{ }^{(19)}$. Entre as células $\mathrm{CD} 3+$, predomina o subtipo $\mathrm{CD} 4$ e a relação CD4/CD8 é acima de 4. A freqüência das células natural killer no $L N$ é muito baixa (aproximadamente $1 \%$ ). A tonsila, ao contrário, é tipicamente um órgão de células B (CD19+). As demais células são $C D 3+$ com predomínio do subtipo $C D 4$ como nos linfonodos ${ }^{(19)}$.

No mundo ocidental, a cada 100 mil pessoas, cerca de 20 novos casos de linfoma são diagnosticados por ano. Deles, 95\% são originários de células B e o restante são doenças malignas de células $\mathrm{T}^{(12)}$. Os linfomas de células $B$ são a maioria entre os linfomas não-Hodgkin e, nesses casos, estabelecer a clonalidade celular, através da restrição de uma das cadeias leves $\kappa$ ou $\lambda$, geralmente é a chave para definir o diagnóstico e a CF é a ferramenta mais conveniente para essa finalidade ${ }^{(11)}$.

Em nosso estudo, em 3/20 casos tipados não foi possível estabelecer a clonalidade devido à equivalente porcentagem de células expressando as cadeias $\kappa \mathrm{e} \lambda$. Dois casos pertenciam ao grupo histológico dos LDGC-B e um era LH, cujas análises morfológicas foram altamente sugestivas desses subgrupos. Segundo estudos de Meda et al. ${ }^{(15)}$ e de Zardawi et al. ${ }^{(24)}$, na ausência da restrição de cadeias leves $\kappa \mathrm{e} \lambda$, outras evidências 
de proliferação clonal podem ser exploradas, como a proliferação de antígenos (CD19, CD20) em grandes proporções em determinados tecidos (superior a $85 \%$ ), CD10 $\geq 18 \%$ ou CD20+CD5+ $\geq 35 \%$.

Em um outro caso não houve expressão de nenhuma das cadeias $\kappa$ ou $\lambda$. Deve-se considerar a ocorrência da expressão verdadeiramente negativa de cadeias leves como padrão aberrante em algumas doenças linfoproliferativas. Esse resultado pode ser utilizado como indicativo de malignidade $(1,10,11,15,23)$.

Um caso de linfoma da zona marginal (CD5-/CD10-) mostrou-se duplamente positivo para $\kappa \mathrm{e} \lambda$. É interessante $\mathrm{o}$ fato de Sigstad et al. ${ }^{(18)}$ também terem observado essa dupla expressão em dois casos também de zona marginal de sua casuística de 102 DLP.

Verificamos que as células do LDGC revelaram-se mais frágeis se comparadas aos demais linfócitos e, como conseqüência, não foram bem representadas nas amostras obtidas pela PAAF. Esse fato foi também observado por Meda et al.(15) e Verstovsek et al. ${ }^{(20)}$. Freqüentemente pode ser caracterizada como uma população equivocadamente policlonal devido à considerável contaminação com células normais residuais. Meda et al. ${ }^{(15)}$ obtiveram em seu estudo 13 casos de amostras inadequadas numa casuística de 275 pacientes. Interessante é o fato de que 11 desses 13 também eram LDGC-B.

O estudo citológico mostrou que $80 \%$ dos casos de LDGC$B$ histologicamente confirmados em nosso trabalho foram altamente sugestivos de linfoma não-Hodgkin (LNH) de grandes células. Assim, um resultado sem evidências de malignidade pela IFT não excluiu um processo neoplásico, reforçando que nestas situações um minucioso exame citomorfológico deve ser realizado ${ }^{(11,15,17)}$. Martins et al. ${ }^{(13)}$, em estudo retrospectivo de 627 materiais de LN obtidos por PAAF, também ressaltam a importância da análise citomorfológica para o estabelecimento de diagnóstico de LNH de grandes células.

Por outro lado, Costa et al.(5) estudaram LNH por PAAF, combinando citologia, imunofenotipagem e estudo do ciclo celular por CF e mostraram que a elevada porcentagem da fase $S$ permitiu distinguir os LDGC-B CD5+ dos linfomas indolentes com acurácia, contribuindo para a diferenciação entre dois tumores de origem similar, porém de agressividades diferentes.

A expressão do antígeno CD5 está presente em alguns linfomas, entre eles o LLPC e o LM, que são dois tipos de DLP de diferentes prognósticos, sendo necessária a correta distinção entre eles. Como estudo adicional é fundamental a caracterização do marcador de ciclina D1, presente em
$70 \%-80 \%$ dos casos de $\mathrm{LM}^{(21)}$. No entanto, essa avaliação é realizada apenas pela imuno-histoquímica, além da detecção da $\mathrm{t}(11 ; 14)$ por citogenética clássica, hibridação in situ por fluorescência (FISH), reação em cadeia da polimerase com transcrição reversa (RT-PCR) ${ }^{(7)}$.

Nos linfomas de células B maduros, o diagnóstico diferencial dos que apresentam o marcador CD10 deve ser feito entre $L F$, linfoma de grandes células e $L B$.

A demonstração do marcador $\mathrm{Bcl}-2$ em histologia auxilia a identificação dos folículos neoplásicos no LF. No entanto, a imuno-histoquímica não permite quantificar essa proteína que está superexpressa no linfoma associado a $\mathrm{t}(14 ; 18)(q 32 ; q 21)$, diferentemente de outros linfomas CD10 positivos e mesmo da hiperplasia folicular reacional em que a expressão é baixa ${ }^{(1,3,4,11)}$.

A CF, pela sua capacidade de análise multiparamétrica, é um excelente método não só para demonstrar a presença como para mensurar produtos em nível intracelular, como a proteína $\mathrm{BCl}-2$, em diferentes tipos de linfomas, podendo auxiliar na sua subclassificação(4).

Este trabalho confirmou maior intensidade média de fluorescência de $\mathrm{BCl}-2$ no LF. Por ser este um dos linfomas mais freqüentes entre os $\mathrm{LNH}$, a aplicação desse marcador no painel de anticorpos agrega valor à identificação dessas doenças por $\mathrm{CF}$, tornando o diagnóstico rápido e mais preciso.

\section{Conclusão}

A PAAF é um procedimento minimamente invasivo no qual a combinação da análise citomorfológica com a imunofenotipagem por CF mostra-se importante ferramenta capaz de rapidamente diferenciar DLP de hiperplasias linfóides reacionais na grande maioria dos casos de linfadenopatias. A introdução do AcMo anti-proteína Bcl-2 agrega valor ao painel de anticorpos no diagnóstico dessas doenças, principalmente identificando o LF pela citometria usando a intensidade média de fluorescência.

\section{Agradecimentos}

À Fundação de Amparo à Pesquisa do Estado de São Paulo (FAPESP), pelo suporte financeiro parcial concedido, e à Dra. Martha Mariana A. S. Arruda, pela concepção das microfotografias. 


\section{Referências}

1. CARAWAY, N. P. Strategies to diagnose lymphoproliferative disease disorders by fine-needle aspiration by using ancillary studies. Cancer, v. 105, n. 6, p. 432-42, 2005.

2. CHUNG, J. et al. Flow cytometric immunophenotyping in fine-needle aspiration of lymph nodes. J Korean Med Sci, v. 14, n. 4, p. 393-400, 1999.

3. COOK, J. R. et al. Bcl-2 expression by multicolor flow cytometric analysis assists in the diagnosis of follicular lymphoma in lymph node and bone marrow. Am J Clin Pathol, v. 119, n. 1, p. 145-51, 2003.

4. CORNFIELD, D. B. et al. Follicular lymphoma can be distinguished from benign follicular hyperplasia by flow cytometry using simultaneous staining of cytoplasmatic $\mathrm{Bcl}-2$ and cell surface CD20. Am J Clin Pathol, v. 114, n. 2, p. 258-63, 2000.

5. COSTA, F. P. S. et al. A utilidade da citologia por punção com agulha fina aliada à imunofenotipagem no diagnóstico dos linfomas não-Hodgkin. Rev Bras Hematol Hemoter, v. 27, n. 1, p. 16-20, 2005.

6. DONG, H. Y. et al. Fine-needle aspiration biopsy in the diagnosis and classification of primary and recurrent lymphoma: a retrospective analysis of the utility of cytomorphology and flow cytometry. Mod Pathol, v. 14, n. 5, p. 472-81, 2001.

7. ELNENAEI, M. O. et al. Cyclin D1 by flow cytometry as a useful tool in the diagnosis of B-cell malignancies. Leuk Res, v. 25, n. 2, p. 115-23, 2001.

8. GUPTA, R. et al. Role of fine-needle aspirate immunophenotyping by flow cytometry in rapid diagnosis of lymphoproliferative disorders. Diagn Cytopathol, v. 35, n. 7, p. 381-85, 2007.

9. HARRIS, N. L. et al. World Health Organization classification of neoplastic diseases of the hematopoietic and lymphoid tissues: report of the Clinical Advisory Committee Meeting. J Clin Oncol, v. 17, n. 12, p. 3835-49, 1999.

10. JENNINGS, C. D.; FOON, K. A. Recent advances in flow cytometry: application to the diagnosis of hematologic malignancy. Blood, v. 90, n. 8, p. 2863-92, 1997.

11. JORGENSEN, J. L. State of the art symposium: flow cytometry in the diagnosis of lymphoproliferative disorders by fine-needle aspiration. Cancer, v. 105, n. 6, p. 443-51, 2005.

12. KÜPPERS, R. Mechanisms of B-cell Iymphoma pathogenesis. Nat Rev Cancer, v. 5, n. 4, p. 25162, 2005.
13. MARTINS, M. R.; SANTOS, G. C. Fine-needle aspiration cytology in the diagnosis of superficial lymphadenopathy: a 5-year Brazilian experience. Diagn Cytopathol, v. 34, n. 2, p. 130-4, 2006.

14. MARTINEZ, A. et al. Routine use of immunophenotype by flow cytometry in tissues with suspected hematological malignancies. Cytometry B Clin Cytom, v. 56, n. 1, p. 8-15, 2003.

15. MEDA, B. A. et al. Diagnosis and subclassification of primary and recurrent lymphoma. Am J Clin Pathol, v. 113, n. 5, p. 688-99, 2000.

16. NICOL, T. L. etal. The accuracy of combined cytopathologic and flow cytometric analysis of fine-needle aspirates of lymph nodes. Am J Clin Pathol, v. 114, n. 1, p. 18-28, 2000.

17. SAPIA, S. et al. Fine-needle aspiration for flow cytometry immunophenotyping of non-Hodgkin lymphoma. Medicina (B. Aires), v. 55, n. 6, p. 675-80, 1995.

18. SIGSTAD, E. et al. The role of flow cytometric immunophenotyping in improving the diagnostic accuracy in referred fine-needle aspiration specimens. Diagn Cytopathol, v. 31, n. 3, p. 159-63, 2004.

19. SZCZEPANSKI, T. etal. Flow cytometric immunophenotyping of normal and malignant lymphocytes. Clin Chem Lab Med, v. 44, n. 7, p. 775-96, 2006.

20. VERSTOVSEK, G. et al. Large B-cell lymphomas: fine-needle aspiration plays an important role in initial diagnosis of cases which are falsely negative by flow cytometry. Diagn Cytopathol, v. 27, n. 5, p. 282-5, 2002.

21. WILLIAMS, M. E. et al. Rearrangement of the chromosome $11 \mathrm{Bcl}-1$ locus in centrocytic lymphoma: analysis with multiple breakpoint probes. Blood, v. 78, n. 2, p. 4938, 1991.

22. WOOD, B. L. et al. 2006 Bethesda International Consensus recommendations on the immunophenotypic analysis of hematolymphoid neoplasia by flow cytometry: optimal reagents and reporting for the flow cytometric diagnosis of hematopoietic neoplasia. Cytometry B Clin Cytom, v. 72, p. S14-22, 2007.

23. YOUNG, N. A. et al. Utilization of fine-needle aspiration cytology and flow cytometry in the diagnosis and subclassification of primary and recurrent lymphoma. Cancer, v. 84, n. 4, p. 252-61, 1998.

24. ZARDAWI, I. M. et al. Flow-cytometric algorithm on fineneedle aspirates for the clinical workup of patients with lymphadenopathy. Diagn Cytopathol, v. 19, n. 4, p. 274-8, 1998.

\begin{tabular}{l|l} 
& Endereço para correspondência \\
\hline & Mihoko Yamamoto \\
Disciplina de Hematologia e Hemoterapia - UNIFESP \\
Rua Botucatu, $740-3^{\circ}$ andar \\
CEP 04023-900 - São Paulo-SP \\
Tel: (11) 5579-1550 \\
Fax: (11) 5571-8806 \\
e-mail: yamamoto@hemato.epm.br
\end{tabular}

